\section{Discussion}

We believe that A.C.T.H. gel by intramuscular injection reduces the incidence of denervation in Bell's palsy to a substantial degree. All the treated patients were fully satisfied with their recovery except for one who developed complete denervation (Langworth and Taverner, 1963 ; Taverner and Fearnley, 1965). On clinical grounds we suspect that this patient was suffering from herpes zoster, which seems to be unresponsive to A.C.T.H.

The premature ending of the trial was unfortunate, but on ethical grounds we were not prepared to withhold treatment in order to strengthen our case at the cost of possible permanent damage to patients. Apart from the clinical results, we were aware on electrophysiological grounds that we were modifying the course of Bell's palsy in an unprecedented manner. In five patients conduction latencies of more than $4 \mathrm{msec}$. were obtained from the affected facial nerve on electrical stimulation, yet these patients recovered completely after A.C.T.H. therapy. Langworth and Taverner (1963) have shown that such values always presage denervation.

It is true that the patients treated later are a selected group, but the bias is against the treatment. The $30(41 \%)$ patients with only conduction block were excluded, but this ensures that the remainder contains a higher proportion than normal of patients likely to develop denervation if untreated. This claim is based upon the fact that at this stage the patients as a whole were unselected, successive patients attending with fresh Bell's palsy in whom about $40 \%$ are likely to develop denervation (see above). Twenty-seven of the treated patients (37\% of the total) had a raised threshold to anodal galvanic stimulation of the tongue when first seen. It has been shown by -Peiris and Miles (1965) that this always means that with standard treatment denervation is going to occur. Their work was completed before the present trial was started, and these patients treated with A.C.T.H. gel are the only exceptions to their findings we have ever seen.

The success of A.C.T.H. in preventing denervation contrasts with the failure of oral cortisone (Tavemer, 1954). This differential effect has been noted previously in neurological conditions (Jönsson et al., 1951 ; Alexander et al., 1958 ; Ross et al., 1958 ; Miller et al., 1961). Perhaps the pattern of hormones liberated by the patient's own suprarenal glands on stimulation lies behind this difference.

Our present policy is to treat all patients with Bell's palsy in whom there is any doubt about the likelihood of complete recovery, because of a raised threshold to anodal galvanic stimulation of the tongue. If the test is unsatisfactory, especially in older patients, then treatment is given anyway.
Patients with severe degrees of diabetes mellitus and congestive heart failure should probably be excluded.

We are satisfied that this form of treatment started on the first day of paralysis will virtually eliminate the often severe permanent disfigurement that has always been the grievous danger after Bell's palsy. This in turn removes the need to establish the value of surgical treatment (Langworth and Taverner, 1963).

\section{Summary}

The results of trials of the use of intramuscular A.C.T.H. gel in the treatment of idiopathic facial paralysis (Bell's palsy) are reported.

Preliminary results of a randomly selected controlled sequential trial with 34 treated and 36 control patients showed a benefit attributable to treatment significant at the $5 \%$ level, but in the final results the differences did not reach statistical significance.

The work was continued, a total of 77 patients being treated with A.C.T.H.-64 recovered completely and 13 developed denervation. From previous studies the expected results in 77 successive patients with Bell's palsy would be 47 complete recoveries and 30 with denervation. The difference is shown to be highly significant.

It is claimed that even better results would be obtained if all patients were treated within 24 hours of the onset of paralysis.

We thank Professor M. Hamilton for his invaluable help in the statistical aspect of this work. We are indebted to Mr. P. J. Burch for much theoretical discussion which led to the initiation of this trial to test a hypothesis. We are grateful to the many doctors who have referred patients so promptly. We are deeply grateful to the chairman and secretaries of the local health committees in Leeds, Bradford, Barnsley, Dewsbury, and the West Riding for their enthusiastic co-operation.

\section{REFERENCES}

Alexander, L., Berkeley, A. W., and Alexander, A. M. (1958). F. Amer.

med. Ass., 166, 1943.
Armitage, P. (1960). Sequential Medical Trials. Blackwell, Oxford.

Fearnley, M. E., Rainer, E. H., Taverner, D., Boyle, T. McM., and Miles, D. W. (1964). Lancet, 2, 725.

Jönsson, B., Reis, G. von, and Sahlgren, E. (1951). Acta psychiat. (Kbh. .), Suppl. No. 74, p. 60.

Krarup, B. (1958). Acta oto-laryng. (Stockh.), 49, 294.

Krarup, B. (1963). Brain, 86, 465.

Langworth, E. P., and Taverner, D. (1963). (1961). Lancet, $2,1120$.

Mosforth, J., and Taverner, D. (1958). Brit. med. F., 2, 675 .

Mosforth, J., and Taverner, D. (1958). Brit. med. J., 2, 675 .
Peiris, O. A., and Miles, D. W. (1965). Ibid., 2, I162. Ross, J., Colman. 475.

Taverner, D. (1954). Lancet, 2, 1052.

(1955). Brain, 78, 209.

- (1959). Proc. roy. Soc. Med., 52, 1077.

- and Fearnley, M. E. (1965). Lancet, 1, 488.

\title{
Detection of Effects of Ionizing Radiation by Population Studies
}

\author{
G. HEMS,* M.SC., PH.D.
}

Brit. med. F., 1966, 1, 393-396

The development and use of atomic energy have led to an increase in man's exposure to ionizing radiation, and there is general concern over the possible damage which might result from this increased exposure. Situations which give rise to large individual doses are extremely rare, and the major exposure is to low doses at very low dose rates. Large numbers of the general population are exposed to fallout at dose rates which average a few hundreths of a rad per year. A small

* Radiological Protection Service (Ministry of Health and Medical Research Council), Sutton, Surrey. section of the population are radiation workers and are exposed, occupationally, to higher doses; these amount, on average, to $1 \mathrm{rad}$ per year, or less. So far, harmful effects of low doses of radiation at low dose rates have not been detected, and the possible risks are estimated by extrapolating from the effects of high doses, delivered at high dose rates, and observed in studies of atomic-bomb survivors, and ankylosing-spondylitis patients who have been treated with ionizing radiation. This extrapolation introduces considerable uncertainty, which might be avoided by attempting to detect directly the effects of exposures 
to low doses at low dose rates. Since at these low doses the risk per individual is very small, a population study is necessary, and an essential requirement of such a study is that the population is large enough for any observed differences between it and a control population to be statistically significant.

If a population study were undertaken to detect radiation effects there would be many practical problems, such as setting up a control population and estimating doses received by large numbers of people. However, the present paper is concerned only with the requirements of minimum population size. Estimates of this minimum population size $(\mathrm{N})$ are given below for the detection of mutations and leukaemia attributable to the increased radiation. These estimates indicate that the minimum population sizes are far larger than those at present available, so that, appealing as such population studies are, it must be concluded that it is unlikely that they can be used to detect radiation effects.

\section{Detection of Genetic Effects}

From genetic studies the rates of several spontaneous mutations are known for man (Penrose, 1957). Estimates for the mutation rates of some dominant characteristics range from 4 per million loci per generation for partial albinism and deafness to around 50 per million loci per generation for chondrodystrophy (Penrose, 1957). For the purpose of the following calculations a general and commonly accepted value (United Nations, 1962, p. 14) of 1 mutation per 100,000 loci per generation will be used. The yield of mutations per rad in man can be estimated from experimental data obtained for selected mutations attributable to the increased radiation in the mouse (Stevenson, 1964). From recent studies (United Nations, 1962 , p. 100, para.149) it appears that, with continuous irradiation of mice at low dose rates, the dose required to double the natural mutation rate is about 150 rads for males and higher for females. These results suggest that the earlier estimate (M.R.C., 1956) of 30-80 rads for the doubling dose in man may have been too low. With normal level of background radiation of about 0.1 rad per year the genetic dose to age 30 years is 3 rads, and so, by taking the genetic doubling dose as 150 rads, one-fiftieth of the spontaneous mutations could be attributed to background radiation. For a population exposed to a level of background radiation $B$ times the normal level the minimum population size $(\mathrm{N})$ which must be studied in order to detect, with a $95 \%$ limit of confidence, a mutation attributable to the increased radiation at a single locus is given by

$$
\frac{N \geqslant 2(99+B) 10^{7}}{(B-1)^{2}}
$$

Values of $\mathrm{N}$ have been plotted against different values of $\mathrm{B}$ (see Chart, upper curve).

The value of $\mathrm{N}$ depends, of course, on the value used for doubling dose. If instead of the likcly value of 150 rads the earlier estimate of 30 rads were used $N$ would be about onetwentieth of the value indicated in the Chart. Also, if the less stringent confidence limit of $68 \%$ were accepted, the minimum population size would be one-quarter of that given in the Chart.

If instead of a single locus several dominant mutations were studied as a group the total incidence of mutations attributable to the increased radiation would be greater and any increase due to radiation could be detected in a correspondingly smaller study population. For, say, 10 dominant mutations, assumed to be of equal radio-susceptibility, mutations attributable to the increased radiation could be detected in a population onetenth of the minimum size necessary to detect a single mutation.

The sex chromosomes provide a special case. Damage at different loci on the sex chromosomes will be reflected in a single parameter, the sex ratio. There will be a large number of loci and the population size necessary to detect a significant change will be correspondingly reduced. This has enabled a change in sex ratio to be detected (Lejeune et al., 1960) in the small population of 1,000 men exposed to $1-10$ rads.

\section{Detection of Radiation-induced Leukaemia}

Three estimates of the theoretical minimum population size required to detect radiation-induced leukaemia have been made independently by Buck (1959), Lindell (1960), and Sowby (1964). These estimates were based on the values, given in Table 1, for the natural incidence of leukaemia and the estimated yield of radiation-induced leukaemia (derived from high-dose experiments). As radiation-induced leukaemias appear over a period of several years after exposure, the yield is expressed as the total incidence per rad together with a statement of the period at risk.

\begin{tabular}{|c|c|c|c|c|}
\hline Reference & Population & $\begin{array}{c}\text { Natural } \\
\text { Incidence of } \\
\text { Leukaemia } \\
\text { per } \\
10^{6} \text { per Year }\end{array}$ & $\begin{array}{l}\text { Period } \\
\text { at Risk } \\
\text { (Year) }\end{array}$ & $\begin{array}{c}\text { Yield of } \\
\text { Leukaemia } \\
\text { Estimated from } \\
\text { Effects of } \\
\text { High Doses }\end{array}$ \\
\hline $\begin{array}{l}\text { Buck (1959) } \\
\text { Lindell (1960) } \\
\text { Sowby (1964) }\end{array}$ & $\begin{array}{l}35-44 \text { age group } \\
\text { Whole population } \\
\text {,y }\end{array}$ & $\begin{array}{l}33 \cdot 2 \\
50 \\
50\end{array}$ & $\begin{array}{l}10 \\
35 \\
15\end{array}$ & $\begin{array}{l}10 / 10^{6} / \mathrm{rad} \\
50 / 10^{6} / \mathrm{rad} \\
15 / 10^{6} / \mathrm{rad}\end{array}$ \\
\hline
\end{tabular}

Buck derived the yield of radiation-induced leukaemia from Court Brown and Doll's (1957) study of ankylosing spondylitics, taking 50 rads as the effective whole-body dose. Buck did not specify the period at risk, but presumably it was the period of observation-namely, 10 years. Lindell assumed that the period at risk equalled the mean half-life ( 35 years), and so, from Lewis's (1957) estimate of one case of radiation-induced leukaemia per million per rad, the highest likely incidence of radiation-induced leukaemia would be 50 per million per rad. Sowby regarded the shorter period at risk of 15 years, supported by studies of atomic bomb survivors, as probably more accurate, so that for a continuously exposed population the incidence of radiation-induced leukaemia would be 15 cases per $10^{6}$ persons exposed to an annual dose of $1 \mathrm{rad}$. From these values the minimum population size required for the number of radiationinduced leukaemias to exceed the natural incidence by two standard deviations has been calculated, and is given in Table II. Sowby's estimate seems the most satisfactory, as it takes into account the "best estimate" for the length of time postirradiation over which radiation-induced leukaemias appear. The minimum population size necessary, according to Sowby's estimate, to permit detection of radiation-induced leukaemia in a population exposed to $B$ times background, with normal background radiation taken as 0.1 rad per year, has been plotted against $B$ (see Chart, lower curve).

TABLE II.-Estimates of Minimum Population Size Necessary to Detect

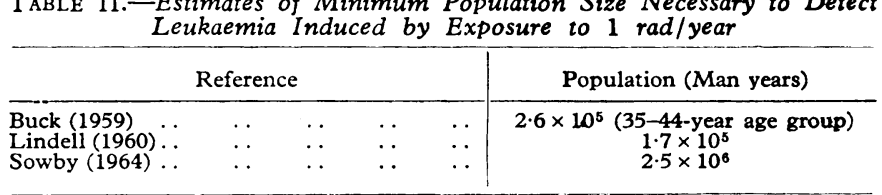

\section{Human Populations Exposed to Radiation}

\section{Natural Background Radiation}

Several regions with high background radiation have been described; these include areas in Brazil, Niue Island, India, and Ceylon. In the United Nations report (1962) Kerala and Madras were judged the largest exposed populations, with 100,000 people exposed on average to $1.3 \mathrm{rads} / \mathrm{year}$. This population is 160 times smaller than the estimated minimum size (see Chart $B=13$ upper curve) of 16 million man-generations necessary to detect a mutation attributable to the increased 
radiation at a single locus. Even if the population size were calculated for the less stringent confidence limit of $68 \%$ and for a lower doubling dose (30 rads) the actual population would be only half the required minimum size. In Rachid (Egypt) 120,000 people are exposed to $0.3 \mathrm{rad} /$ year; this gives an effective population size of 36,000 man-rads/year, which is less than a quarter of that for the Kerala population.

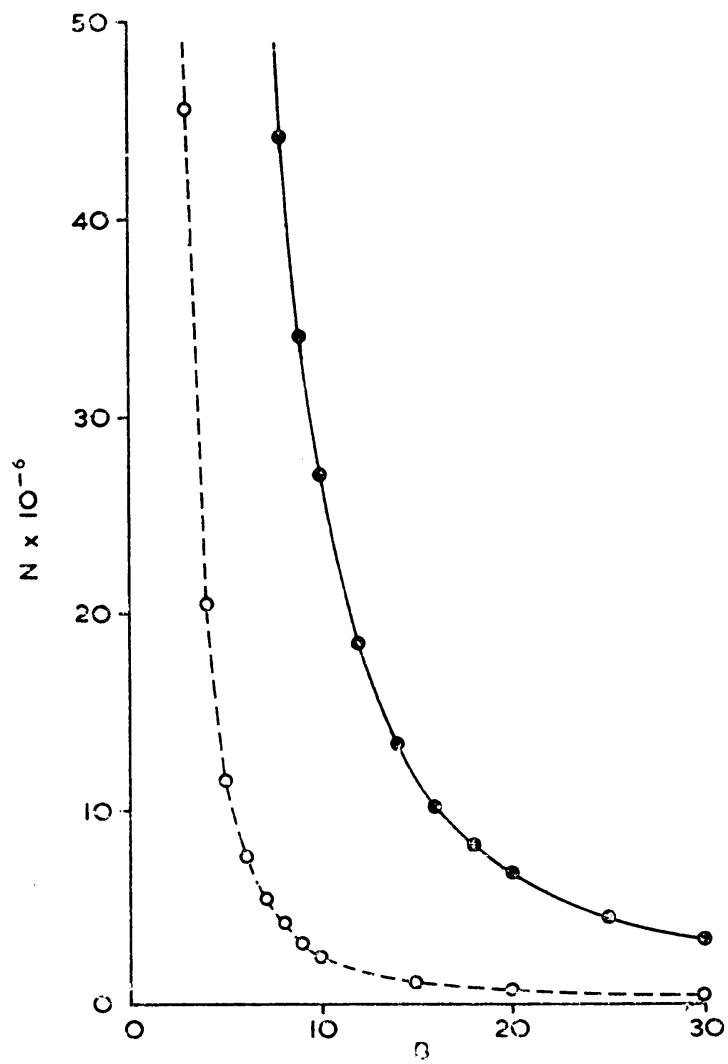

The minimum size (N) of a population, continuously exposed to $\mathrm{B}$ times the normal level of background radiation (assumed to be $0.1 \mathrm{rad} /$ year), necessary to detect a mutation attributable to the increased radiation at a single locus (upper curve , $\mathrm{N}$ in man-generations) and radiation-induced leukaemia (lower curve $\mathrm{O}-\mathrm{O}, \mathrm{N}$ in man-years).

It was estimated that the population of Aberdeen received a bone-marrow dose from natural background radiation of 101 mrads/year compared with 80 mrads/year in Edinburgh. When Court Brown et al. (1960) examined the incidence of leukaemia in the two cities they compared all cases which had been recorded over 17 years, and so with 180,000 inhabitants of Aberdeen the effective population was about 3 million manyears. To detect radiation-induced leukaemia in this population the annual dose would need to be about 900 mrads (see Chart, $\mathrm{B}=9$ lower curve). Although Court Brown et al. (1960) did find a higher incidence of leukaemia in Aberdeen (46 per 10\% year) than in Edinburgh (33 per $10^{6} /$ year), they considered the difference too great to have risen from radiation and ascribed the excess to other unspecified differences between the two populations.

Grahn and Kratchamn (1963) examined the variation of neonatal death rate and birth weight with environmental radiation and altitude. The extremes of dose rate were 103 and 177 mrads/year. The neonatal death rate was greater in mountainous regions, but there was no correlation with levels of environmental radiation. The higher death rate at greater altitude was attributed to a lowered oxygen tension, though the mechanism was not understood. Since the way in which radiation might contribute to neonatal death, or to changes in birth weight, is not known, it is not possible to estimate the magnitude of the minimum population size. This study does illustrate how in a population study to detect radiation effects the effect of factors other than radiation have to be taken into account.

\section{Cosmic-ray Effects}

Dose from cosmic rays increases with altitude and with geomagnetic latitude. The highest cosmic-ray dose where a large population could be expected is 80 mrads/year at $3,000 \mathrm{~m}$. above sea-level and 60 degrees geomagnetic latitude (Lindell and Dobson, 1961). If background radiation other than cosmic is about $70 \mathrm{mrads} /$ year the highest total level of background radiation is about $150 \mathrm{mrads} /$ year. If $\mathrm{B}=1.5$ a population of $45 \times 10^{6}$ man-years must be studied in order to detect radiationinduced leukaemia (see Chart, lower curve). This is far larger than any human population living at $3,000 \mathrm{~m}$. above sea-level and at 60 degrees geomagnetic latitude, and so it is most unlikely that population studies could detect effects of cosmic rays on man.

Craig and Seidman (1961) compared the incidence of leukaemia and lymphoma in the United States with cosmic-ray intensity. The extreme difference in cosmic-ray intensity was only $8 \%$ with less than $11 \times 10^{6}$ persons exposed at the highest level. This population is small compared with the estimated necessary size. Hence, radiation-induced leukaemia could be detected only if the leukaemogenic efficiency of cosmic rays was greater by several orders of magnitude than that usually attributed to them. Craig and Seidman did not find any correlation of leukaemia or lymphoma incidence with cosmic-ray intensity.

\section{Occupational Exposure}

A worker exposed to the maximum permitted whole-body dose of $5 \mathrm{rads} /$ year from age 18 to 30 accumulates a genetic dose, including background radiation, of 63 rads-that is, an average dose rate of $2.1 \mathrm{rads} /$ year. To detect a mutation at a single locus induced by this level of exposure it would be necessary to study at least $6 \times 10^{6}$ man-generations (see Chart, $\mathrm{B}=21$, upper curve) of fully exposed workers.

For the detection of radiation-induced leukaemia it is more appropriate to consider a population of workers fully exposed for more than 15 years-that is, at ages greater than 33 years. At this age the natural annual incidence of leukaemia is 33 per million (Penrose, 1957). The standard error of this incidence is 5.8 , and so, in order to detect radiation-induced leukaemia, the exposed population must be large enough for the number of radiation-induced leukaemias to be greater than 11.6 per $10^{6}$. For full occupational exposure of 5 rads/year the expected annual number of cases of radiation-induced leukaemia is 75 per $10^{6}$, so that the minimum population size would be:

$$
\frac{11.6}{75} \times 10^{6}=1.55 \times 10^{5} \text { man-years. }
$$

These estimates for the minimum number of fully exposed radiation workers necessary to permit detection of a mutation attributable to the increased radiation at a single locus, and radiation-induced leukaemia, may be compared with the occupational exposure of radiation workers in the U.K. In 1960, in the U.K. Atomic Energy Authority were 17,830 persons under monitoring control for external radiation, and the integrated dose to the Authority's employees was 8,700 man-rads, estimated from the dose recorded by the film badge in excess of threshold (Marley, 1965). During the year the exposure of 1,829 persons exceeded 1.5 rads. Among the 18,283 persons to whom film badges were issued by the Radiological Protection Service during 1960, only 420 received a dose, estimated from their film badge, in excess of 1.5 rads (Greenslade, 1965). Thus the total number of persons exposed during 1960 in excess of 1.5 rads was 2,249 , in these two groups, which are the greater part of the total occupational exposure in the U.K. If these 
2,249 persons were all exposed to 5 rads, and in practice their exposure was on average much lower, the exposed group would still be less than $2 \%$ of the minimum size (in man-years) to permit detection of radiation-induced leukaemia and an even smaller fraction of the size (in man-generations) required for detection of a mutation attributable to the increased radiation.

\section{Summary and Conclusions}

In order to detect radiation effects by a population study it is, of course, essential that the population be large enough for the radiation effects to be statistically significant. For exposure of man to low doses of radiation at low dose rates the minimum population size to permit detection of radiation-induced leukaemia is many tens of thousands of man-years; for detection of dominant mutations attributable to the increased radiation the necessary population (in man-generations), as estimated from mouse data, is even larger. Exposed populations which have been surveyed so far are smaller than the minimum theoretical size and would need to be studied for an impracticably long time before either a mutation attributable to the increased radiation at a single locus or radiation-induced leukaemia could be detected. Stevenson (1957), in his examination of this problem, also concluded that it appeared unlikely that populations could be found of sufficient size to permit detection of mutations induced by background radiation.

In conclusion it should be emphasized that, in addition to the difficulty of fulfilling the requirement for a minimum popula- tion size, if a population study were undertaken to detect radiation effects additional practical problems are likely to be encountered in setting up a satisfactory control population (Grünberg, 1964) and in assessing mean annual doses.

\section{REFERENCES}

Buck, C. (1959). Science, 129, 1357.

Court Brown, W. M., and Doll, R. (1957). Spec. Rep. Ser. med. Res. Coun. (Lond.), No. 295.

- Spiers, F. W., Duffy, B. J., and McHugh, M. J. (1960). Brit. med. 7., 1,1753 .

Craig, L., and Seidman, H. (1961). Blood, 17, 319.

Grahn, D., and Kratchman, J. (1963). Amer. F. hum. Genet., 15, 329.

Greenslade, E. (1965). Radiological Protection Service, Personal communication.

Grüneberg, H. (1964). Nature (Lond.), 204, 222.

Lejeune, J., Turpin, R., and Rethore, M. O. (1960). IXth International Congress of Radiology (Proceedings), p. 1089.

Lewis, E. B. (1957). Science, 125, 965.

Lindell, B. (1960). The Use of Vital and Health Statistics for Genetic and Radiation Studies (A/AC/.82/Seminar).

- and Dobson, R. L. (1961). Wld Hlth Org. Publ. Hlth Pap., No. 6.

Marloy, W. G. (1965). Authority Health and Safety Branch, U.K. Atomic Energy Authority, Personal communication.

Medical Research Council (1956). The Hazards to Man of Nuclear and Allied Radiation (Cmd. 9780). H.M.S.O., London.

Penrose, L. S. (1957). Effect of Radiation on Human Heredity, p. 101. W.H.O., Geneva.

Sowby, D. (1964). Personal communication.

Stevenson, A. C. (1957), Effect of Radiation on Human Heredity, p. 125. W.H.O., Geneva.

(1964). Personal communication.

United Nations (1962). Report of the United Nations Scientific Committee on the Effects of Atomic Radiation, p. 14. New York.

\title{
Hepatic Folate in Man
}

\author{
I. CHANARIN,* M.B., CH.B., M.D., D.C.P.; M. HUTCHINSON,† B.A., B.SC. ; ANNE MCLEAN, $\ddagger$ PH.D. \\ MARGARET MOULE,§ M.S.
}

Brit. med. F., 1966, 1, 396-399

Tests of folic-acid function are widely used in the investigation of patients with megaloblastic anaemia. These tests are the urinary excretion of formiminoglutamic acid and the direct assay of the serum (or whole blood) concentration of various forms of folate by microbiological assay. Results with these tests have been reviewed in a recent symposium at the Royal Society of Medicine (Herbert, 1964 ; Chanarin, 1964).

Abnormal results with both these tests are frequent in hospital patients who are haematologically normal, and it is uncertain whether these abnormal values indicate subclinical folate deficiency or merely the unsatisfactory nature of the tests. The purpose of this study was to correlate the results of these tests of folic-acid function with direct assay of the amount of folic acid in the tissues. The liver is the most satisfactory tissue for this purpose, since it contains most of the folates in the body and is the site of the important synthetic reactions involving the folate coenzymes. Donaldson and Keresztesy (1959) have found that hepatic folate in the horse is 5-methyltetrahydropteroyl-monoglutamate. This paper also reports observations on the nature of the folate compounds in human liver.

\section{Materials and Methods}

Observations were made on 26 patients admitted to the surgical wards with a variety of disorders (see Table), and who were all undergoing a laparotomy. The day before operation a blood sample was obtained for a full blood count, including enumeration of five-lobed neutrophils, and for the microbiological assay of the levels of serum folate and vitamin $B_{12}$. Fifteen grammes of 1 -histidine-mono- $\mathrm{HCl}$ was given orally and urine collected for eight hours for the estimation of formiminoglutamic-acid excretion. At laparotomy a small liver biopsy was taken by the surgeon. The liver was either processed immediately for assay of its folate content or stored in a dry, sealed, container at $-20^{\circ} \mathrm{C}$. for a few days before processing. Liver biopsies were also obtained from two patients with megaloblastic anaemia due to folic-acid deficiency. In both patients the cause of the megaloblastic anaemia was excessive alcohol consumption associated with a poor diet. Two samples of liver obtained at necropsy were also studied.

All the surgical patients in our study were truly volunteers. The procedure was explained to them some days before the operation, and their willingness to co-operate was obtained. Further, the consent of the surgeon in charge of the patient was also obtained, and the taking of the very small biopsy was entirely at the discretion of the surgeon at the operationand indeed in some cases this was not obtained.

\footnotetext{
* Senior Lecturer in Haematology.

+ Medical Student.

$¥$ Member of the Scientific Staff.

Member of the Scientific Staff.

M.R.C. Experimental Haematology Research Unit and Department of M.R.C. Experimental Haematology Research Unit and Department of
Haematology, The Wright-Fleming Institute of Microbiology, St. Mary's Hospital Medical School, London.
} 